\title{
Effects of Low-Molecular-Weight-Organic-Acids on the Release Kinetic of Organochlorine Pesticides from Red Soil
}

\author{
Zhao Zhenhua ${ }^{1}$, Xia Liling 2 , Wang Fang ${ }^{3}$ and Jiang Xin ${ }^{3}$ \\ ${ }^{1}$ State key laboratory of hydrology-water resources and hydraulic engineering, \\ Hohai University, \\ ${ }^{2}$ Nanjing Institute of Industry Technology, \\ ${ }^{3}$ State Key Laboratory of Soil and Sustainable Agriculture Institute of Soil Science, \\ Chinese Academy of Sciences,
}

China

\section{Introduction}

Organochlorine pesticides (OCPs) had been widely used in the world. Due to their strong persistence (The biological half-life period of DDT can reach 10 years in the soil (Li et al., 1999), the biological half-life period of DDE is longer than DDT((ATSDR), 1994)), high enrichment capability and amplification capability and potential high toxicity. They have been banned since the early 1970s in the global scope in succession, and China also banned these pesticides in 1983. After decades of biodegradation, its residual concentration in soil has been reduced significantly (Generally ranges from several to several hundred ng/g). But through the enrichment amplification of food chain, it still has high detection rate in soil, vegetables and human milk. DDE and DDD are the aerobic and anaerobic degradation products of DDT respectively, their insecticidal broad-spectrum and toxicity are higher than the DDT. As a kind of environmental estrogens, it may cause some damage to the health of human body and reproductive system (Maness et al., 1998; Romieu et al., 2000); hexachloroclohexanes (HCHs) have 8 kinds of isomers $\left(a-, \beta-, \delta_{-}^{-}, \varepsilon^{-}, \gamma_{-}^{-}, \eta_{-}^{-}, \theta_{-}^{-}\right.$, and $l-\mathrm{HCH}^{-}$, and $\gamma$-HCH has obvious insecticidal efficacy (ATSDR), 1994). These two types of organochlorine pesticides are typically persistent organic pollutants (POPs).

The solubility of OCPs in water is low and the transference capability of OCPs in the soil is limited, but dissolved organic matter (DOM) in the environment could obviously change the transference behaviour of OCPs, and the predecessor's research mainly focuses on the influence of macromolecular DOM to the migration behaviour of OCPs, and the mechanism lies mainly on its chelation behaviour to OCPs (Chiou et al., 1987; Chiou et al., 2000; Chiou et al., 1986; Hassett \& Anderson, 1982; Landrum et al., 1984), studies about the effect of low molecule weight DOM on the retained behaviour of OCPs have rarely seen. In the rhizosphere microenvironment, the existence of low molecular organic acids (LMWOA) of plant root exudates must have great influence on the migration of OCPs, the experiment conducted by White (2003) showed that the seven kinds of low molecular weight organic acid could significantly increase the desorption of $\mathrm{p}, \mathrm{p}^{\prime}-\mathrm{DDE}$, the increment could reach at the range of 19\%-80\% (White \& Kottler, 2002; White et al., 2003). 
The object of this article is to discusses the dynamic release behavior of several organochlorine pesticides like DDT isomer (DDTs) and $\mathrm{HCH}$ isomer (HCHs) with LMWOA from variable charge soil (red soil) with self-designed dynamics device, and provide some reference to the migration and fate of these kinds of substances and also the phytoremediation and ecological risk assess ment of organic pollutants in the environment .

\section{Research advance}

Their source include: root exudates, microorganisms, animals, and the degradation of organic matters. The LMWOA, as one of the typical rhizosphere active components presenting in soil and a key molecule in the solubilization of phosphorus-containing crystalline or amorphous minerals or as a desorbing agent for orthophosphate adsorbed on other soil minerals, is sure to have an influence on the existing state of organochlorine pesticides in soil and on the interaction between organochlorine pesticides and soil colloids.

\subsection{Source of LMWOA}

Low-molecular-weight organic acids (LMWOAs) occur widely in soils and primarily originate from root exudation (Gao et al., 2010; Ling et al., 2009; Lu et al., 2007; White et al., 2003). Moreover, microorganisms, animals, and the degradation of organic matters can also produce LMWOA (Jones, 1998). People have noted the role of root exudates in the early 18th century, and then have a more profound understanding of the composition and the role of plant root exudates in latest 30 years. The composition and transportation of root exudates and its function in soil structure formation, soil mineral weathering, soil nutrient activation, promoting the nutrient absorption and rhizospheric soil nutrient movement and poison resistance (Al, acid) have been reported (Oburger et al., 2009; Strom et al., 2001; van Hees et al., 2002; van Hees et al., 2003). Root exudates are lubricant of the root - soil interface and microbial energy source, and they can improve the rhizosphere environment. They are the key materials for plants to adapt to nutritional stress (Strom et al., 2002; Strom et al., 2005) and environmental stress (do Nascimento et al., 2006; Gao et al., 2010; Guo et al., 2007; Jones et al., 2001; Liao et al., 2006; Luo et al., 2006; Toyama et al., 2011; Zhu et al., 2009). There are over 200 kinds of root exudates, including saccharides, organic acids, amino acids and allelochemicals, as well as small amount of fatty acids and steroids and trace growth substances and enzymes (Baudoin $e t$ al., 2003; Muratova et al., 2009). Their types and numbers will vary with the plant types and rhizosphere environment. Among them, the LMWOA are the main component of root exudates, which with one to several carboxyl and the most common LMWOAs identified in soils include citric acid, tartaric acid, maleic acid, malic acid, formic acid, acetic acid, oxalic acid, succinic acid, fumaric acid, propionic acid and so on (Baudoin et al., 2003; Kpomblekou-A $\&$ Tabatabai, 2003). Most of them are the intermediate products of tricarboxylic acid cycle. In special cases, plant secretes specific organic acids, such as mugineic acid which is secreted by rice and wheat when they lack iron (Inoue et al., 2009; Kobayashi et al., 2010). Molecular structure and charged characteristics of LMWOA can affect many processes in the soil, some stresses of adversity factor can induce plant roots to secrete a large number of organic acids, and this is an adaptive reaction of plant to ecological environment (Inoue et al., 2009; Kobayashi et al., 2010). 


\subsection{Residual characteristic of organochlorine pesticides in soil and rhizosphere}

Organochlorine pesticides (OCPs) could quickly be adsorbed or bound to the soil or soilorganic matter due to their high hydrophobicity and low water solubility after they were introduced into the soil. With time, the diminishes of these OCPs's bioavailability due to an "aging" effect and the formation of "bound-residues", which takes place during processes of decomposition and humification of organic matter (Alexander, 2000). The residual charactaristics of OCPs in rehizosphere and bulk soil maybe related to the properties of OCPs (water solubility, degradability, volatility,etc.), characteristic of soil mineral (the type and content of organic matter, diameter composition of soil mineral particle, content of oxidationreduction materials, moisture content, etc.), properties of plant (root system characteristic, kind and quantity of root exudates, lipoprotein content, specific surface, etc.) (Alexander, 2000; Calvelo Pereira et al., 2006; Chen et al., 2007; Gonzalez et al., 2005; Inui et al., 2008; Mikes et al., 2009; Mo et al., 2008; Skaates et al., 2005; White et al., 2002; Yang et al., 2008; Yao et al., 2007). For the OCPs with high volatility and relative easy degradation, the concentrations in rehizosphere are generally lower than that in bulk soil, and the results generally appear in the indoor simulation experments. For the OCPs with low volatility and relative harddegradation, the concentrations in rehizosphere are generally higher than that in bulk soil, and the results generally appear in the field experments. The results of pot experiment maybe also differ with field experiment for the same compounds. This kind of contradictory results is mainly due to the pollution sources can be repeatedly inputted by irrigation and dry and wet deposition in field, pollutants would be enrich in rehizosphere with water flow; and the pollution source is single input in indoor simulation experiment, plant absorption or biodegradation result in the concentration of OCPs in rhizosphere soil is lower then in the bulk soil.

For example, Chen et al. (2007) showed that the measured DDXs in the rhizosphere soils were significantly higher than those in the bulk soils. p, $\mathrm{p}^{\prime}-\mathrm{DDT}, \mathrm{p}, \mathrm{p}^{\prime}-\mathrm{DDD}$, and p, $\mathrm{p}^{\prime}-\mathrm{DDE}$ in the soil accounted for $38 \%, 47 \%$ and $15 \%$ of the total. For total DDXs, approximately one third remained on the outer surface of the roots. The partition of DDXs between rhizosphere soil and root surface depended on contaminant affinity to soil organic matter, soil organic matter content and root specific area (Chen et al., 2007), Calvelo Pereira et al. (2006) reported that the roots of Avena sativa L., Chenopodium spp., Solanum nigrum L., Cytisus striatus (Hill) Roth, and Vicia sativa L. tended to reduce levels of the $\mathrm{HCH}$ isomers in the rhizosphere (Calvelo Pereira et al., 2006), white et al. (2002) found that the chlordane concentration in the rhizosphere (soil attached to roots) was significantly less than that in the bulk soil. However, the enantiomeric ratio of the chiral components and overall component ratios had changed little in the rhizosphere relative to the bulk soil. (White et al., 2002).

\subsection{Interaction mechanism between LMWOA and pesticides in soil}

LMWOAs have been shown to disrupt the sequestering soil matrix, thereby enhancing the desorption of organic pollutants in soil (White et al., 2003). Consequently, it is expected that LMWOAs, in theory, may affect OCPs availability in soil environment. However, to date, few research has been conducted in this area, and there is limited information on the availability and sorption-desorption behaviour of OCPs from natural soils by organic acids. Gonzalez et al. (2010) showed that sodium citrate and oxalate, at levels usually exuded by plant roots, effectively enhanced desorption of p,p'-DDT, p,p'-DDE and a-cypermethrin, while no effects were observed for a-endosulfan and endosulfan sulfate, the non-ionic surfactant 
Tween 80 behaved similarly to the acids, whereas the anionic sodium dodecyl sulfate enhanced desorption of all pesticides (Gonzalez et al., 2010). Luo et al. (2006) reported that soil organic carbon played a predominant role in the retention of DDT. Oxalate significantly increased the desorption of p,p'-DDT, with the largest increments ranging from $11 \%$ to $54 \%$ for different soils. Oxalate addition also resulted in the increased release of dissolved organic carbon and inorganic ions from soils. Root exudates had similar effects to those of oxalate and significantly increased DDT desorption from the soils. So, Low molecular weight dissolved organic carbon amendments caused partial dissolution of the soil structure, such as the organo-mineral linkages, resulting in the release of organic carbon and metal ions and thus the subsequent enhanced desorption of DDT from the soils (Luo et al., 2006).

We can put forward some mechanisms about the LMWOA or root exudates with OCPs desorption: (1) Mechanism of minerals dissolution. LMWOA induced the dissolution of soil minerals and resulted in the desorption of OCPs adsorbed by soil minerals; (2) Mechanism of indirect release. Soil inherent organic matter is dissolved and released by LMWOA and resulted in the desorption of OCPs adsorbed by soil inherent organic matter. (3) Mechanism of direct release. The LMWOA directly chelated with OCPs and released it. (4) Mechanism of locking and unlocking. LMWOA interacted with soil inherent organic matter like a key and induced the change of its conformation and properties, resulted in the OCPs were locked or unlocked by soil inherent organic matter (Figure 1).

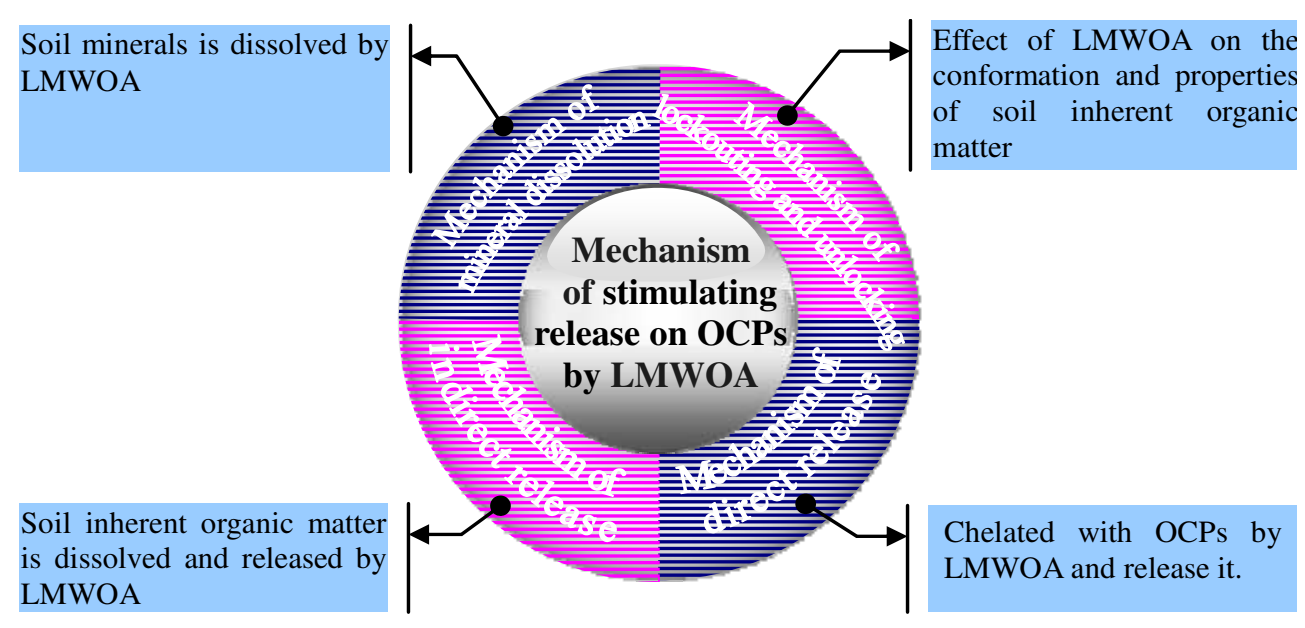

Fig. 1. Mechanism obout the stimulating release of OCPs by LMWOA

\section{Release kinetic of organochlorine pesticides from soil in LMWOA system}

\subsection{Materials and methods}

\subsubsection{Instruments and reagents}

n-Hexane (chromatographically pure, Tedia Company, USA); petroleum ether with boiling range of $60{ }^{\circ} \mathrm{C}$ to $90{ }^{\circ} \mathrm{C}$ (analytical reagent, Hangzhou Refinery, Zhejiang Province, P.R. China); methylene chloride, acetone and concentrated sulfuric acid (analytical reagent, Nanjing Chemical Reagent Plant, P.R. China); anhydrous sodium sulfate (analytical reagent, it was sieved by boult of 200 mesh, then treated at $225^{\circ} \mathrm{C}$ for $4 \mathrm{~h}$ and stored in sealed 
container before use); Organochlorine pesticides standard (o, p'-DDT, o, p'-DDE, p, p'-DDT, $\mathrm{p}, \mathrm{p}^{\prime}-\mathrm{DDD}, \mathrm{p}, \mathrm{p}^{\prime}-\mathrm{DDE}, \alpha-, \beta-, \gamma-$ and $\left.\delta-\mathrm{HCH}\right)$ were purchased from Dr. Ehrenstorfer Company, Germany. The characteristics of pesticides studied are listed in table 1.

\begin{tabular}{|l|c|c|c|c|c|}
\hline \multicolumn{1}{|c|}{ DDTs } & solubility & $\log$ Kow & HCHs & solubility & $\operatorname{logKow}$ \\
\hline $\mathrm{p}, \mathrm{p}^{\prime}-\mathrm{DDT}$ & $1.2 \sim 5.5^{11}$ & $6.2 \sim 6.91$ & $\alpha$-HCH & 10 & 3.8 \\
\hline $\mathrm{o}, \mathrm{p}^{\prime}$-DDT & $1.2 \sim 5.5$ & 6.76 & $\beta-\mathrm{HCH}$ & 5 & 3.78 \\
\hline $\mathrm{p}, \mathrm{p}^{\prime}-\mathrm{DDE}$ & 65 & $5.69 \sim 6.96$ & $\gamma \mathrm{HCH}$ & $7.3 \sim 17$ & $3.61,3.72$ \\
\hline $\mathrm{o}, \mathrm{p}^{\prime}$-DDE & 65 & 6.94 & $\delta$-HCH & 1 & 4.14 \\
\hline
\end{tabular}

1) Solubility in water at $24 \sim 25^{\circ} \mathrm{C}, \mu \mathrm{g} / \mathrm{L}$

Table 1. Some properties of the organochlorine pesticides (Chiou et al., 1987; Harald et al., 2000)

Agilent-6890 GC/ECD gas chromatography and HP7683 automatic sampler with HP chemical workstation (Hewlet-Packard, USA) and HP-5 fused capillary column $(30 \mathrm{~m} \times 320$ $\mu \mathrm{m} \times 0.25 \mu \mathrm{m})$ as chromatographic column; Sigma $2-16 \mathrm{~K}$ high speed freezing centrifuge (Sigma, Germany); water bath rotary vacuum evaporator (Yarong Biochemical Instrument Plant, Shanghai, P.R.China); HS-10360D ultrasonic cleaning machine (Heng'ao Science and Technology Company, Tianjin, P.R.China); BS200S-WE1 electronic balance (1/10000, Sartorius Company, Germany); SPP cartridge and filter disc (Chemical and Physical Institute of National Chromatogram Center in Dalian, P.R.China).

Celite 545 (chromatographic grade, $0.020-0.045 \mathrm{~mm}$, Serva Company) was dried in muffle furnace at $550{ }^{\circ} \mathrm{C}$ for $4 \mathrm{~h}$, then treated at $200{ }^{\circ} \mathrm{C}$ in oven before addition of $3 \%$ of deionized water to deactivate it, and stored in a sealed container before use; Purified SPE column was prepared by packing with a teflon filter disc $+1 \mathrm{~g}$ celite $545+1 \mathrm{~g}$ anhydrous sodium sulfate + a teflon filter disc.

\subsubsection{Chromatogram conditions}

Initial oven temperature was kept at $60^{\circ} \mathrm{C}$ for $1 \mathrm{~min}$. Then the temperature was increased to $140{ }^{\circ} \mathrm{C}$ at a speed of $20^{\circ} \mathrm{C} \mathrm{min}-1$ and subsequently increased to $280{ }^{\circ} \mathrm{C}$ at a speed of $12{ }^{\circ} \mathrm{C}$ $\mathrm{min}^{-1}$ and kept at $280^{\circ} \mathrm{C}$ for $4 \mathrm{~min}$. The injector temperature was set as $220^{\circ} \mathrm{C}$, while the detector temperature was set as $280^{\circ} \mathrm{C}$. High purity $\mathrm{N}_{2}(99.999 \%)$ was used as carrier gas at a flow rate of $2 \mathrm{~mL} \mathrm{~min}{ }^{-1}$. $2 \mu \mathrm{L}$ of sample was injected in a splitless mode. Quantitative calculation was conducted with external standard method.

\subsubsection{Dynamic experiment methods}

Soil sample The red soil, Hydragric Acrisols - according to WRB (World Reference Base for soil resources) (ISSS/ISRIC/FAO, 1998), was sampled at depths of $5 \mathrm{~cm}$ to $20 \mathrm{~cm}$ from the Red Soil Ecologic Experimental Station of Chinese Academy of Science in Yingtan, Jiangxi province, P. R. China $\left(28^{\circ} 12^{\prime} 34.1^{\prime \prime} \mathrm{N}, 116^{\circ} 55^{\prime} 32.3^{\prime \prime} \mathrm{E}\right)$, lyophilized and sieved $(\leq 1 \mathrm{~mm})$ for further analysis. The clay minerals of soil sample were mainly composed of kaolinite and hydroxyaluminum vermiculite, and contained a spot of hydromica and a trace amount of gibbsite. The main physical and chemical characteristics of the soil were as follows: $\mathrm{pH} 5.07$, clay content $32.3 \%$, organic matter content $1.14 \%$, Cation Exchange Capacity (CEC) $10.10 \mathrm{Cmol}(+) \mathrm{kg}^{-1}$.

Spiked soil Soil samples were sieved to $<2 \mathrm{~mm}$ and stored at room temperature until spiking procedure. Spiked soil samples were prepared by adding $500 \mu \mathrm{L}$ of standard mixture of 13 kinds of OCPs (the concentration is $10 \mathrm{ng} \mu \mathrm{L}^{-1}$ for each compound dissolved 
in n-hexane) to $20 \mathrm{~g}$ of soil according to the reference (Tor et al., 2006). This spike level corresponds to $250 \mu \mathrm{g} \mathrm{kg}-1$. Then $20 \mathrm{~mL}$ of acetone was added and suspension was mixed for 30 min with a mechanical shaker. After the bulk of the solvent was evaporated at room temperature, the samples were stored at $4{ }^{\circ} \mathrm{C}$ in stoppered glass bottle for six month in the dark. Then the extractions were carried out.

Preparation of eluent 3 kinds of low molecular weight organic acid eluent solutions (oxalic acid, tartaric acid and citric acid) were all prepared as $10 \mathrm{mmol} / \mathrm{L}$ solutions by the analytical reagents, and their $\mathrm{pH}$ were adjusted to 5.5 by $\mathrm{NaOH}$ or $\mathrm{HNO}_{3}$. The eluent's $\mathrm{pH}$ selected was based on the common $\mathrm{pH}$ of southern variable charge soil in China.

The dynamic devices are as follows: (1)Storage Bottles; (2) P200Iltype high performance liquid chromatography pump (Scientific Instruments Co., Ltd. YiLite, Dalian, P. R. China); (3)dynamic reaction cell made of PTFE to provide reaction space; (4SBS-100 automatic fraction collector (Huxi Analytical Instrument Factory Co., Ltd, Shanghai, P. R. China).

Dynamics experiment methods Weigh $7 \mathrm{~g}$ of spiked soil, put it into the dynamic reaction cell, and seal the cell tightly after wetting the sample with distilled water. The upper and lower ends of dynamic reaction cell, respectively, connected with the automatic fraction collector and high performance liquid chromatography pump. The leaching velocity was set for $1 \mathrm{~mL} / \mathrm{min}$, the collection time of each glass tube was 10 minutes and continuously collected 100 glass tubes of leacheate. The experimental temperature of the dynamic reaction cell was controlled at $298 \pm 0.5 \mathrm{~K}$ by using thermostatic waterbath. When the samples were determined, two glass tubes were combined as one test sample point.Transferred the collected liquid into separating funnel, and add $10 \mu \mathrm{L}$ of internal standard (Five chlorine nitrobenzene methanol solution, $5 \mathrm{ng} / \mu \mathrm{L}$ ). After homogeneous mixing, added $10 \mathrm{~mL}$ petroleum ether and $0.5 \mathrm{~g} \mathrm{NaCl}$ in the separating funnel, and oscillated for liquid-liquid extraction. After adding $0.5 \mathrm{~mL}$ of acetone to eliminate stubborn emulsification phenomenon, transferred organic extraction phase into pear-shaped bottle, and then added $10 \mathrm{~mL}$ petroleum ether to repeat the extraction step. These two extract were combined and put it in pear-shaped bottle. The extract was concentrated to about $1 \mathrm{~mL}$ by rotary evaporators, and translated it into purifying SPE column. The SPE column was eluted with $10 \mathrm{~mL}$ of $10 \%$ dichloromethane / petroleum ether $(\mathrm{V}: \mathrm{V})$, and the leacheate was concentrated to about $1 \mathrm{~mL}$ by rotary evaporators again and blew by nitrogen and metered volume to $1 \mathrm{~mL}$ by $\mathrm{n}$-hexane. Determined by GC-ECD, and quantified by external standard method. The results showed that, the recovery rate of this liquid-liquid extraction method was $80 \% \sim 105 \%$ to different pesticides, and the relative standard deviation was $3 \% \sim 8 \%$, which meet the demands of the analysis of trace organic compounds.

\subsubsection{Quality control and data analysis}

Laboratory blank values for all the compounds were generally low and posed no problem to the analytical quantification. The overall reproducibility was evaluated using the replicate analyses $(n=3)$. The coefficient of variation $(\mathrm{CV})$ was between 0.01 and 0.35 for the various compounds, and it was less than 0.3 in $90 \%$ of the cases. Therefore, the reproducibility of the measurements was considered to be satisfactory.

\subsection{Results and discussion}

\subsubsection{Effects of LMWOA on the release rate of organochlorine pesticides}

The average releasing rate is calculated by the each pesticides quantity contained in leaching solution $(20 \mathrm{~mL})$ divided by elution volume. From figure 2, the release rate of $\mathrm{HCHs}$ by 
water and organic acids is much higher than that of DDTs, the difference is about 3 times. The release ability of water to DDTs is very low. This kind of pesticides is released by water at a certain concentration which practically is lower than its solubility, concentration, the elution volume does not have evident effects to its release rate. The release pattern of $\mathrm{HCHs}$ with high solubility by water follows a quick release at first, and then a slow release after an elution inflection point at which the elution volume is about $300 \mathrm{~mL}$ when it achieves the elution inflection point.
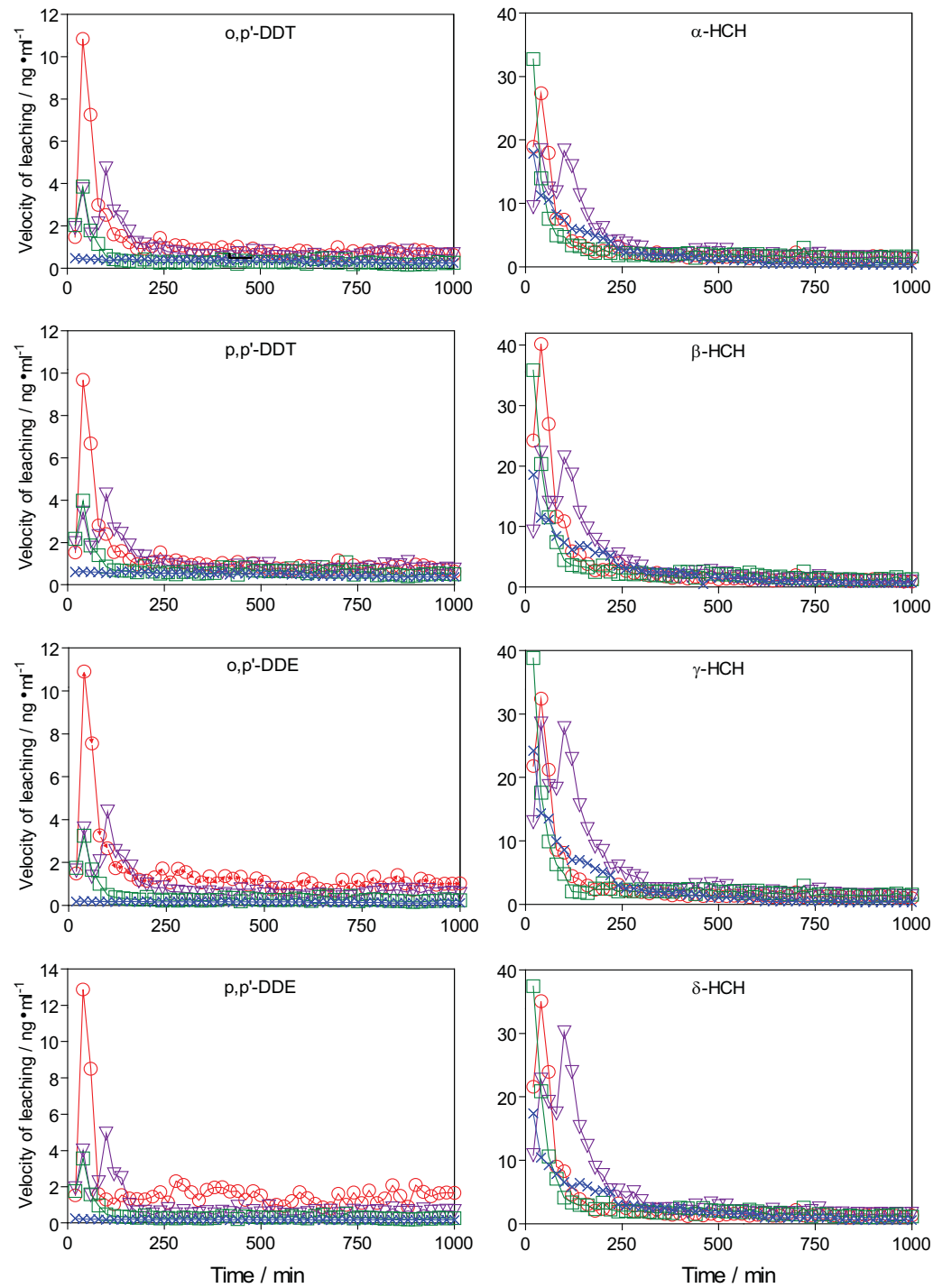

Fig. 2. Release velocity of organochlorine pesticides from red soil with LMWOA.-*-:water , 口- : oxalate , - $\nabla$ - : tartrate , - - : citrate 
The release pattern of DDTs by oxalic acid is single-peak type curve. That means the release rate increases along with the elution volume increase, and it reaches the maximum elution rate when the elution volume is $40 \mathrm{~mL}$, after that the rate gradually decreases, and it is not stable until the volume reaches to $120 \mathrm{~mL}$. The release pattern of DDTs by oxalic acid is the same to that by water except that the elution inflection point is $120 \mathrm{~mL}$.

The release patterns of DDTs and HCHs by tartaric acid belong to bimodal curve. When the volume of leacheate was $40 \mathrm{~mL}$, the release rate of the two kinds of pesticides reached maximum, and then the rate slightly decreased. When the volume of leacheate increased to about $100 \mathrm{~mL}$, the rate reached another maximum. And it became stable till the volume reached $240 \mathrm{~mL}$. The release pattern of DDTs and $\mathrm{HCHs}$ by citric acid solution was also single-peak type curve, and their inflection point appeared at about $140 \mathrm{~mL}$.

The existence form of organochlorine pesticide in soil includes free form, loose bound form and tight bound form (for example aging residual form). When the leaching solution flowed through the soil, the free form and loose bound form would be released firstly, after loose bound form was eluted completely, the tight bound form OCPs were slowly dissolved out with approximately constant speed. The leaching pattern of OCPs by tartaric acid displayed the bimodal curve, it maybe relate to the comparatively weak elution ability to loose bound form pesticides. The first peak represents the release of free form pesticides, the second peak represents the release of loose bound form pesticides, and then the slow release of the tight bound form. This indicates that the release intensity of tartaric acid to the loose bound form pesticides is smaller than the citric acid. As the citric acid has stronger desorption ability to the free form and loose bound form pesticides, these two forms pesticides will be leached out the soil together and form a single peak.

\subsubsection{The cumulative release of organochlorine pesticides from soil by LMWOA}

Figure 2 shows the diagram of the cumulative release of organochlorine pesticides by several LMWOA from red soil. Table 2 lists the fitting results of the dynamic release data of organochlorine pesticides to several common kinetic equation, while $t$ is the time, $Q t$ is the cumulative release amount of pesticides, $a$ and $b$ are the parameters of the kinetic equation (with different meaning in different equations), $k$ is the apparent speed constant in the firstlevel dynamic equation, $q_{\max }$ is the apparent equilibrium desorption amount. The multiple correlation coefficient $\left(R^{2}\right)$ and standard error $(S e)$ can be used to judge the degree of fitting. That is to say the larger $R^{2}$ and the smaller $S e$ contribute to a better fitting degree.

$$
s_{e}=\sqrt{\frac{\sum\left(s_{t}-\hat{s}_{t}\right)^{2}}{n-2}}, R^{2}=1-\frac{\sum\left(s_{t}-\hat{s}_{t}\right)^{2}}{\sum\left(s_{t}-\bar{s}_{t}\right)^{2}}
$$

Where the $S_{t}, \hat{s}_{t} 、 \bar{s}_{t}$ and $n$ are the measured value, the predictive value, the average value and sample number, respectively.

Figure 3 shows that the introduction of LMWOA strengthens the release of organochlorine pesticides to a certain extent (compared with water, it increases by 15 18 percentage for DDTs, while the HCHs increases by 7 25 percentage). The release ability of LMWOA for DDTs is: citric acid $(18 \sim 26 \%)>$ tartaric acid $(14 \sim 20 \%)>$ oxalic acid $(6 \sim 10 \%)>$ water $(3 \sim 8 \%)$. On the other hand, the release ability of LMWOA for HCHs is: tartaric acid $(60 \%)>$ citric acid $(49 \sim 55 \%)>$ oxalic acid $(41 \sim 48 \%)>$ water $(35 \sim 41 \%)$. The results match the experiment results conducted by White who used batch method and pot experiment to study the effect of 7 kinds of LMWOA to p, p' - DDE (White et al., 2003). 

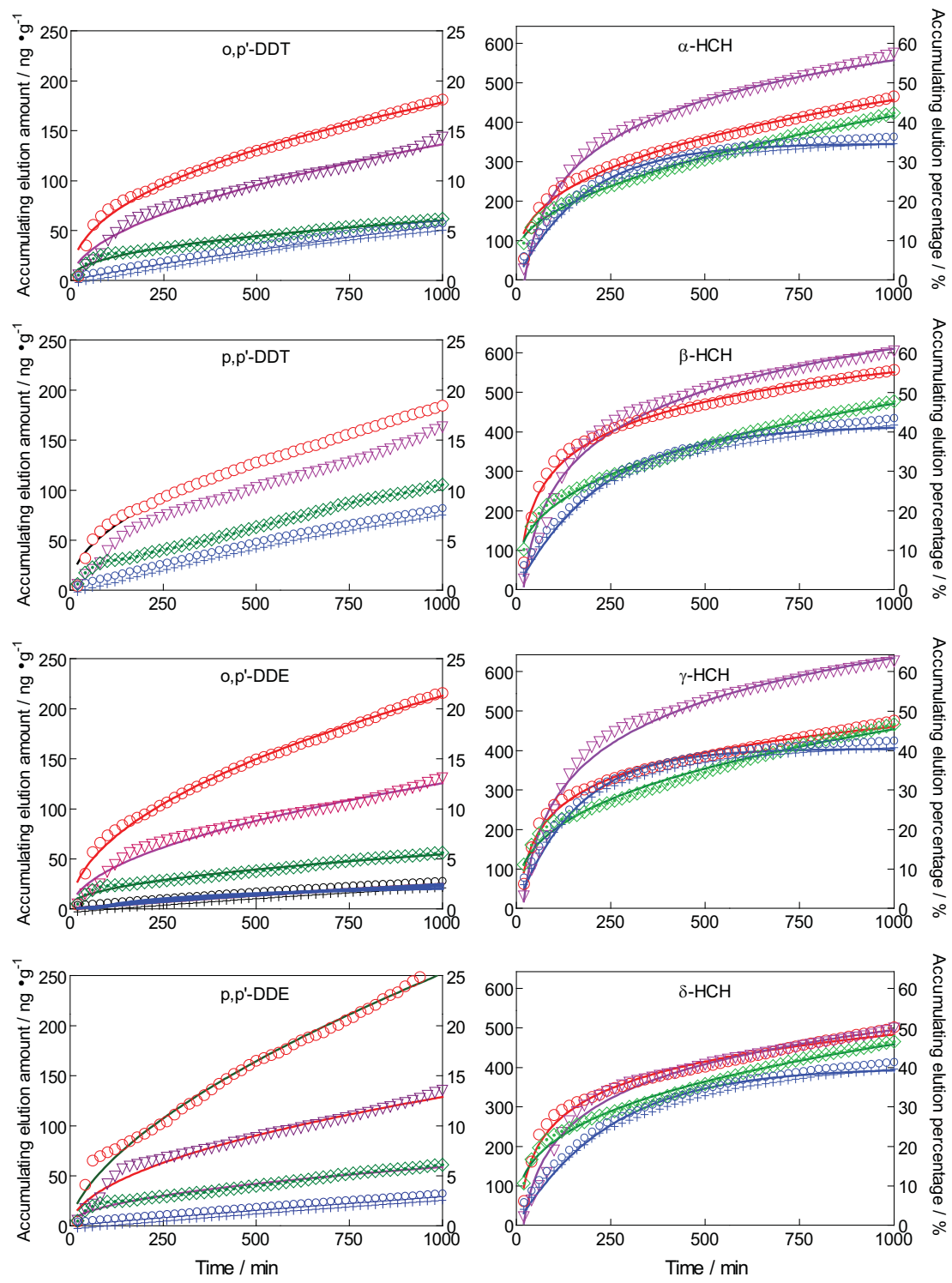

Fig. 3. Accumulative release kinetic of organochlorine pesticides from red soil with LMWOA leaching. -*-:water , - + : oxalate , - - : tartrate , -०- : citrate

Table 2 shows that the kinetic release of organochlorine pesticides in water system is basically accord with the first-order kinetic equation $\left(R^{2}: 0.99-0.9999, \mathrm{p}<0.0001\right), \mathrm{p}, \mathrm{p}^{\prime}-\mathrm{DDE}$ appears to be more consistent with two-constant equation (its $S e$ is lower than that of the 


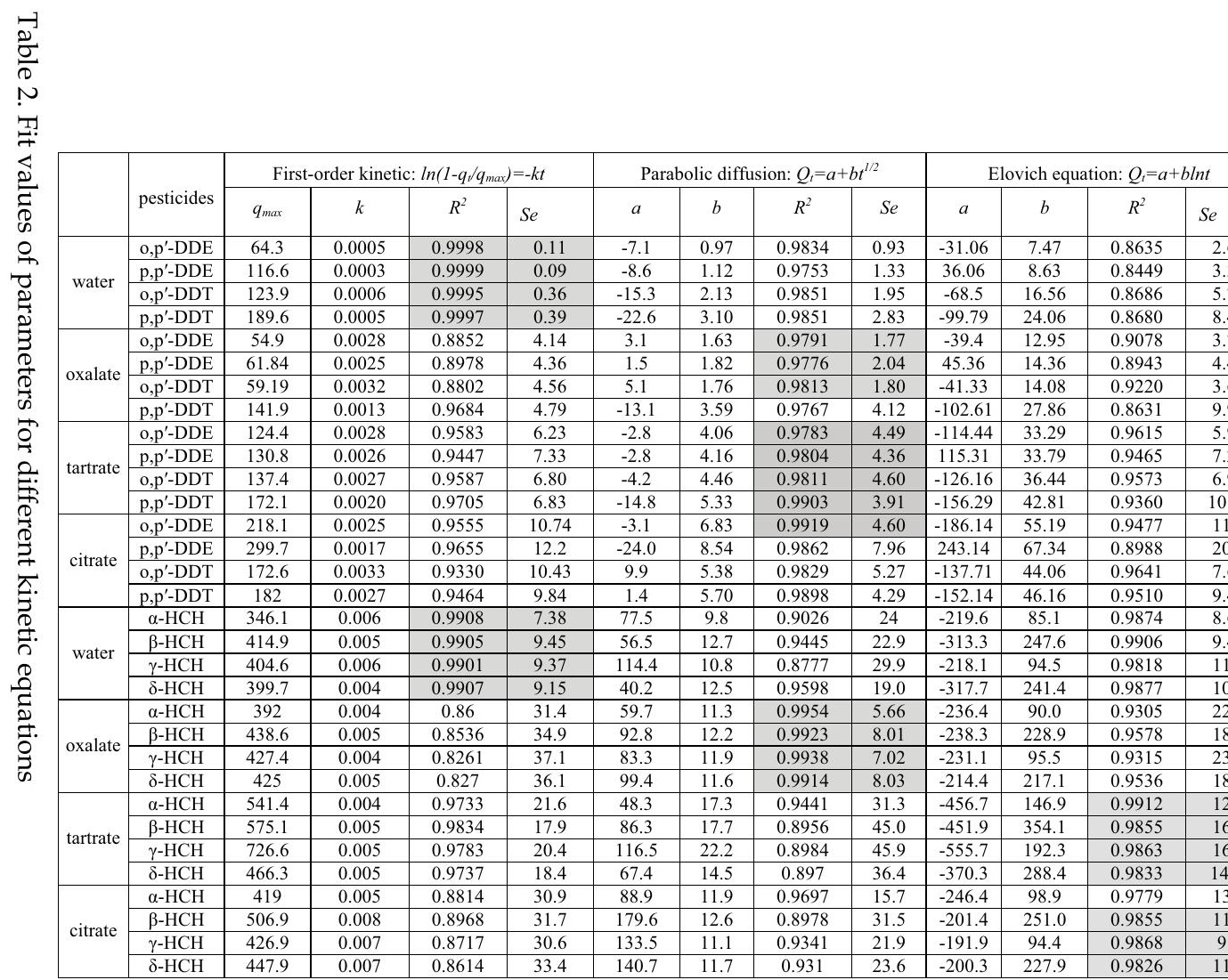


first order equation), and it implies that the release kinetics of the organochlorine pesticides studied in water is still a surface diffusion on soil particles. The kinetic release of $o, p^{\prime}$ and $p$, p'-DDE, o, p'-DDT and HCHs by oxalic acid seems to be more consistent with the parabolic diffusion equation, and it indicates that the release is controlled by a number of diffusion mechanism, the outward diffusion process of the pesticides from soil particle interior is the limit step of the whole release process; but p, p' - DDT more conforms to the double constant equation, it may be related to the dissolution and the heterogeneity of energy of soil particles surface induced by oxalic acid (activation and inactivation function of granular surface). In tartaric acid system and citric acid system, the parabola diffusion equation (tartaric acid system) and the double constant equation (citric acid system) may be better to describe the kinetic release behaviours of DDE and DDT; Besides a-HCH conforms to the double constant equation, the kinetic release of $\beta-, \gamma$ - and $\delta-\mathrm{HCH}$ seem to be more consistent with the Elovich equation. And it tells us that in the tartaric acid leaching system. So the release of DDTs is mainly characterized by several diffusion mechanisms in the tartaric acid leaching system and characterized by the release mechanism of different energy position in citric acid system. It may involve some more complex release mechanisms for the release of the $\mathrm{HCHs}$, which own a larger solubility in water.

Overall, the release of organochlorine pesticides in water system is consistent with the firstorder kinetic equation which is good at describing a simple diffusion mechanism. The release of DDTs by the oxalic acid and citric acid system can be well described by doubleconstant equation which is good at describing a uniform energy distribution; that in tartaric acid system can be describe by parabolic diffusion equation which is controlled by a number of diffusion mechanism. For HCHs, their release behaviour in oxalic acid system conforms to parabolic diffusion equation, and that in tartaric acid and citric acid system are more consistent with Elovich equation .

\subsubsection{Discussion on the release mechanism of organochlorine pesticides by LMWOA}

The difference of organochlorine pesticides release pattern in different LMWOA systems may be related to the differences of the pesticides' three-dimensional structure and different action mechanism of LMWOA on different bound pesticides on the soil surface. Hydrophobic pesticides are adsorbed mainly through hydrophobic force, van der Waals force, hydrogen bonding and other in soil internal space systems, inorganic mineral surface (surface physical adsorption), amorphous organic matter (soft carbon, fast linear distribution) and aggregate organic matter (hard carbon, slow linear adsorption) four regions, especially in the latter two regions that the inherent soil organic matter (SOM) contributed the most, and the soft carbon-bound pesticide has not solute competition and hysteresis of sorption and desorption, which explains the fast and slow release process (Chiou et al., 1986). LMWOA with Carboxyl and hydroxyl can affect the migration of pesticides by competitive adsorption, structural changes (such as the aggregate decentralized by chelating the metal ions that acting as cross-linking agent in the SOM) of soil and SOM, the release (Chiou et al., 2000) and mineral dissolution (Landrum et al., 1984), their release ability to pesticides related to their ability of the dissolution to soil minerals and multi-coordination ability (Yang et al., 2001). Oxalic acid with smaller molecule volume has two activity carboxyl functional groups, citric acid with larger molecule has three carboxyl and one hydroxyl, and tartaric acid have two carboxyl and two hydroxyl groups (Figure. 4). The effect of LMWOA on pesticides bound to soil organic matter includes unlocking action 
and locking action, if the activated pesticides do not leave the reaction system, they may soon be locked and bound with SOM, and resulted in the pesticide level in the system to reduce. Locking and unlocking mechanism to pesticides is the dominant mechanism for oxalic acid with smaller molecule, and the action mechanism of tartaric acid and citric acid with larger molecules to pesticides dominated by the chelation is the same as to macromolecules DOM (Yang et al., 2001) and unlocking mechanism, it can avoid free pesticides being locked again, Therefore, the release amount of pesticides by tartaric acid and citric acid is much higher than that by oxalic acid and water.

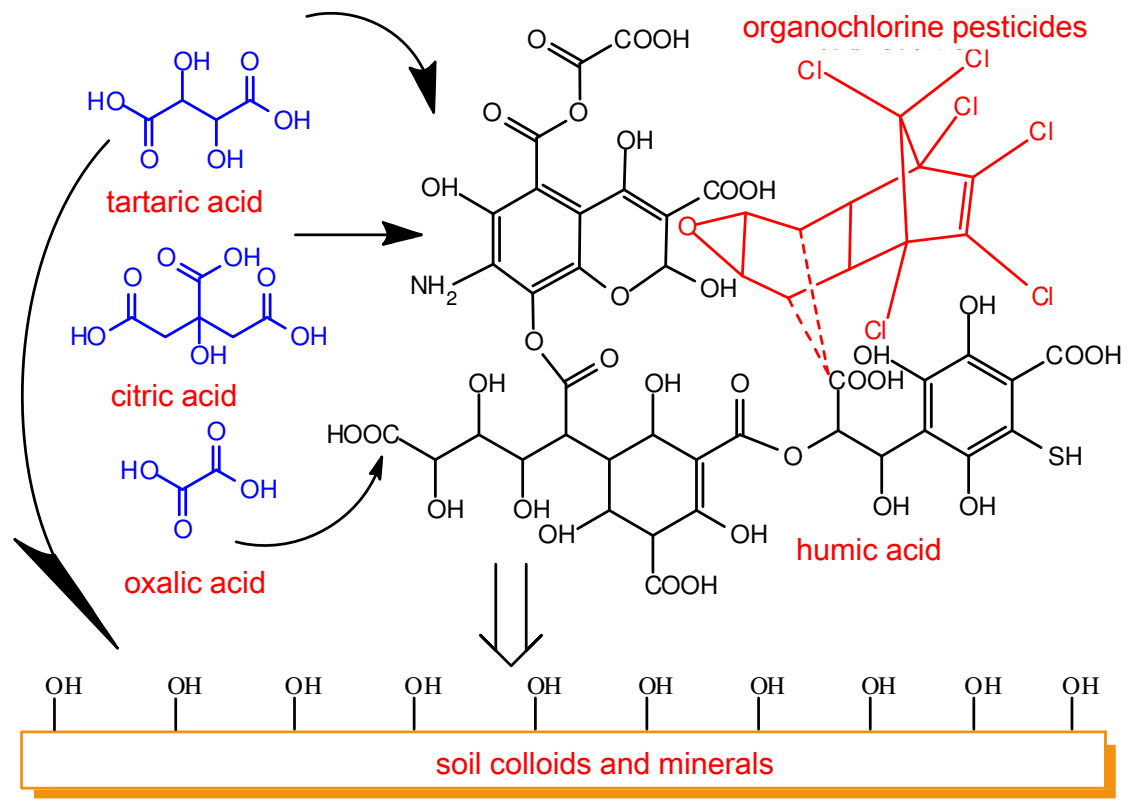

Fig. 4. Sketch about the interaction among pesticides, LMWOA, humic acids and soil mineral.

\section{Conclusion}

The results showed that the introduction of LMWOA could accelerate the release of the tested organochlorine pesticides (relative to the water, increased $15 \% \sim 18 \%$ for DDTs, $7 \% \sim 25 \%$ for $\mathrm{HCHs}$ ). It implied that the LMWOA induced the complication of the kinetics release mechanisms of organochlorine pesticides (The best kinetics equation describing the release of pesticide changed from the first-order kinetic equation in water system to parabola diffuse equation, double constant equation or Elovich equation in LMWOA systems). It also indicated that the kinetics release mechanisms of OCPs by LMWOA involved not only the simple granular surface diffusion mechanism in water system, but also the outward diffusion mechanism of soil particles internal, activation and inactivation function of granular surface, the non-uniform mechanism of surface energy distribution induced by the solution of soil mineral and structure change of soil inherent organic matter coating onto the soil mineral surface by LMWOA. 
The release velocity of HCHs was far higher than that of DDTs by water and LMWOA. Their difference was nearly 3 times. The variation amplitude of the release velocity and the influence of elution volume on release velocity for DDTs by water were all small and not obvious. The release velocity curves of OCPs from soil by LMWOA were all peak-type curve, and it included 2 stages which are rapid release and low release.

\section{Acknowledgment}

The authors would like to acknowledge National Science and Technology major program (2009ZX 07317-007), National Natural Science Foundation of China (50839002), Ministry of Education Key Laboratory of Integrated Regulation and Resource Development on Shallow Lakes foundation, Hohai University (2007KJ003) and the Fundamental Research Funds for the Central Universities (2009B17014).

\section{References}

(Atsdr), A. F. T. S. a. D. R. (1994), 'Toxicological profile for 4,4`-ddt. 4,4-dde, 4,4-ddd( update)', in, (U.S. Dept. of Health and Human Service, TP-93/ 05).

Alexander, M. (2000), 'Aging, bioavailability, and overestimation of risk from environmental pollutants'. Environ. Sci. Technol., Vol. 34, pp. 4259-4265.

Baudoin, E., Benizri, E. and Guckert, A. (2003), 'Impact of artificial root exudates on the bacterial community structure in bulk soil and maize rhizosphere'. Soil Biology and Biochemistry, Vol. 35, No. 9, pp. 1183-1192.

Calvelo Pereira, R., Camps-Arbestain, M., Rodríguez Garrido, B., et al. (2006), 'Behaviour of [alpha]-, [beta]-, [gamma]-, and [delta]-hexachlorocyclohexane in the soil-plant system of a contaminated site'. Environmental Pollution, Vol. 144, No. 1, pp. 210-217.

Chen, S. H., F.L, X., R, D., et al. (2007), 'Adsorption and absorption of dichlorodiphenyltrichloroethane (ddt) and metabolites (ddd and dde) by rice roots'. Environmental Pollution, Vol. 147, pp. 256-261.

Chiou, C. T., Kile, D. E., Brinton, T. L., et al. (1987), 'A compararison of water solubility enhancements of organic solutes by aquatic humic materials and commercial humic acids'. Environ Sci Technol, Vol. 21, No. 12, pp. 1231-1234.

Chiou, C. T., Kile, D. E., Rutherford, D. W., et al. (2000), 'Sorption of selected organic compounds from water to a peat soil and its humic-acid and humin fractions: Potential sources of the sorption nonlinearity'. Environ. Sci. Technol., Vol. 34, No. 7, pp. 1254-1258.

Chiou, C. T., Malcolm, R. L., Brinton, T. I., et al. (1986), 'Water solubility enhancement of some organic pollutants and pesticides by dissolved humic and fulvic acids'. Environ. Sci. Technol., Vol. 20, No. 5, pp. 502-508.

Do Nascimento, C. W. A., Amarasiriwardena, D. and Xing, B. (2006), 'Comparison of natural organic acids and synthetic chelates at enhancing phytoextraction of metals from a multi-metal contaminated soil'. Environmental Pollution, Vol. 140, No. 1, pp. 114-123.

Gao, Y., Ren, L., Ling, W., et al. (2010), 'Desorption of phenanthrene and pyrene in soils by root exudates'. Bioresource Technology, Vol. 101, No. 4, pp. 1159-1165.

Gonzalez, M., Miglioranza, K. S. B., Aizpún De Moreno, J. E., et al. (2005), 'Evaluation of conventionally and organically produced vegetables for high lipophilic 
organochlorine pesticide (ocp) residues'. Food and Chemical Toxicology, Vol. 43, No. 2, pp. 261-269.

Gonzalez, M., Miglioranza, K. S. B., Aizpún, J. E., et al. (2010), 'Assessing pesticide leaching and desorption in soils with different agricultural activities from argentina (pampa and patagonia)'. Chemosphere, Vol. 81, No. 3, pp. 351-358.

Guo, T.-R., Zhang, G.-P., Zhou, M.-X., et al. (2007), 'Influence of aluminum and cadmium stresses on mineral nutrition and root exudates in two barley cultivars'. Pedosphere, Vol. 17, No. 4, pp. 505-512.

Harald, J. G., Gerhard, G. R., Irene, S., et al. (2000), 'Bioaccumulation and occurrence of endocrine-disrupting chemicals (edcs), persistent organic pollutants (pops), and other organic compounds in fish and other organisms including humans', in B. Beek (ed), The handbook of environmental chemistry, (Springer-Verlag, Berlin Heidelberg).

Hassett, J. P. and Anderson, M. A. (1982), 'Effect of dissolved organic matter on adsorption of hydrophobic organic compounds by river and sewage sludge-borne particles'. Water Research, Vol. 16, pp. 681-686.

Inoue, H., Kobayashi, T., Nozoye, T., et al. (2009), 'Rice osysl15 is an iron-regulated iron(iii)deoxymugineic acid transporter expressed in the roots and is essential for iron uptake in early growth of the seedlings'. J Biol Chem, Vol. 284, No. 6, pp. 3470-9.

Inui, H., Wakai, T., Gion, K., et al. (2008), 'Differential uptake for dioxin-like compounds by zucchini subspecies'. Chemosphere, Vol. 73, No. 10, pp. 1602-1607.

Isss/Isric/Fao (1998), 'World reference base for soil resources', in, (Wageningen, Rome).

Jones, D. L. (1998), 'Organic acid in the rhizosphere-a critical review'. Plant Soil, Vol. 205, pp. $25-44$

Jones, D. L., Eldhuset, T., De Wit, H. A., et al. (2001), 'Aluminium effects on organic acid mineralization in a norway spruce forest soil'. Soil Biology and Biochemistry, Vol. 33, No. 9, pp. 1259-1267.

Kobayashi, T., Nakanishi, H. and Nishizawa, N. K. (2010), 'Recent insights into iron homeostasis and their application in graminaceous crops'. Proceedings of the Japan Academy Series B Physical and Biological Sciences, Vol. 86, No. 9, pp. 900-13.

Kpomblekou-A, K. and Tabatabai, M. A. (2003), 'Effect of low-molecular weight organic acids on phosphorus release and phytoavailabilty of phosphorus in phosphate rocks added to soils'. Agriculture, Ecosystems E Environment, Vol. 100, No. 2-3, pp. 275-284.

Landrum, P. F., Nihart, S. R., Eadie, B. J., et al. (1984), 'Reverse-phase separation method for determining pollutant binding to aldrich humic acid and dissolved organic carbon of natural waters'. Environ. Sci. Technol., Vol. 18, No. 3, pp. 187-192.

Li, Z., Shang, L., Zhang, L., et al. (1999), 'Control strategies of malaria in henan province, china. Southeast asian'. J. Trop. Med. Public. Health,, Vol. 30, p. $240 \sim 242$.

Liao, Y. C., Chien, S. W. C., Wang, M. C., et al. (2006), 'Effect of transpiration on pb uptake by lettuce and on water soluble low molecular weight organic acids in rhizosphere'. Chemosphere, Vol. 65, No. 2, pp. 343-351.

Ling, W., Ren, L., Gao, Y., et al. (2009), 'Impact of low-molecular-weight organic acids on the availability of phenanthrene and pyrene in soil'. Soil Biology and Biochemistry, Vol. 41, No. 10, pp. 2187-2195. 
Lu, H. L., Yan, C. L. and Liu, J. C. (2007), 'Low-molecular-weight organic acids exuded by mangrove (kandelia candel (1.) druce) roots and their effect on cadmium species change in the rhizosphere'. Environmental and Experimental Botany Vol. 61, pp. 159166.

Luo, L., Zhang, S., Shan, X.-Q., et al. (2006), 'Oxalate and root exudates enhance the desorption of p,p'-ddt from soils'. Chemosphere, Vol. 63, No. 8, pp. 1273-1279.

Maness, S. C., Mc Donnell, D. P., Gaido, K. W., et al. (1998), ' Inhibition of androgen receptor-dependent transcriptional activity by ddt isomers and methoxychlor in hepg2 human hepatoma cells'. Toxicol. Appl. Pharmacol., Vol. 151, No. 1, pp. 135-142.

Mikes, O., Cupr, P., Trapp, S., et al. (2009), 'Uptake of polychlorinated biphenyls and organochlorine pesticides from soil and air into radishes (raphanus sativus)'. Environmental Pollution, Vol. 157, No. 2, pp. 488-496.

Mo, C.-H., Cai, Q.-Y., Li, H.-Q., et al. (2008), 'Potential of different species for use in removal of ddt from the contaminated soils'. Chemosphere, Vol. 73, No. 1, pp. 120-125.

Muratova, A., Pozdnyakova, N., Golubev, S., et al. (2009), 'Oxidoreductase activity of sorghum root exudates in a phenanthrene-contaminated environment'. Chemosphere, Vol. 74, No. 8, pp. 1031-1036.

Oburger, E., Kirk, G. J. D., Wenzel, W. W., et al. (2009), 'Interactive effects of organic acids in the rhizosphere'. Soil Biology and Biochemistry, Vol. 41, No. 3, pp. 449-457.

Romieu, I., Hernarde, A. M., Lazcano, P. E., et al. (2000), 'Breast cancer, lactation history , and serum organochlorines'. Am. J. Epidmiol., Vol. 152, No. 4, pp. 363-370.

Skaates, S. V., Ramaswami, A. and Anderson, L. G. (2005), 'Transport and fate of dieldrin in poplar and willow trees analyzed by spme'. Chemosphere, Vol. 61, No. 1, pp. 85-91.

Strom, L., Owen, A. G., Godbold, D. L., et al. (2001), 'Organic acid behaviour in a calcareous soil: Sorption reactions and biodegradation rates'. Soil Biology and Biochemistry, Vol. 33, No. 15, pp. 2125-2133.

Strom, L., Owen, A. G., Godbold, D. L., et al. (2002), 'Organic acid mediated p mobilization in the rhizosphere and uptake by maize roots'. Soil Biology and Biochemistry, Vol. 34, No. 5, pp. 703-710.

Strom, L., Owen, A. G., Godbold, D. L., et al. (2005), 'Organic acid behaviour in a calcareous soil implications for rhizosphere nutrient cycling'. Soil Biology and Biochemistry, Vol. 37, No. 11, pp. 2046-2054.

Tor, A., Aydin, M. E. and zcan, S. (2006), 'Ultrasonic solvent extraction of organochlorine pesticides from soil'. Analytica Chimica Acta, Vol. 559, No. 2, pp. 173-180.

Toyama, T., Furukawa, T., Maeda, N., et al. (2011), 'Accelerated biodegradation of pyrene and benzo[a]pyrene in the phragmites australis rhizosphere by bacteria-root exudate interactions'. Water Research, Vol. 45, No. 4, pp. 1629-1638.

Van Hees, P. a. W., Jones, D. L. and Godbold, D. L. (2002), 'Biodegradation of low molecular weight organic acids in coniferous forest podzolic soils'. Soil Biology and Biochemistry, Vol. 34, No. 9, pp. 1261-1272.

Van Hees, P. a. W., Vinogradoff, S. I., Edwards, A. C., et al. (2003), 'Low molecular weight organic acid adsorption in forest soils: Effects on soil solution concentrations and biodegradation rates'. Soil Biology and Biochemistry, Vol. 35, No. 8, pp. 1015-1026.

White, J. C. and Kottler, B. D. (2002), 'Citrate-mediated increase in the uptake of weathered p,p'-dde residues by plants'. Environ. Toxic. Chem., Vol. 21, pp. 550-556. 
White, J. C., Mattina, M. I., Eitzer, B. D., et al. (2002), 'Tracking chlordane compositional and chiral profiles in soil and vegetation'. Chemosphere, Vol. 47, No. 6, pp. 639-646.

White, J. C., Mattina, M. I., Lee, W.-Y., et al. (2003), 'Role of organic acids in enhancing the desorption and uptake of weathered p,p'-dde by cucurbita pepo'. Environmental Pollution, Vol. 124, No. 1, pp. 71-80.

Yang, H., Zheng, M. and Zhu, Y. (2008), 'Tracing the behaviour of hexachlorobenzene in a paddy soil-rice system over a growth season'. Journal of Environmental Sciences, Vol. 20, No. 1, pp. 56-61.

Yang, Y., Ratte, D., Smets, B. F., et al. (2001), 'Mobilization of soil organic matter by complexing agents and implications for polycyclic aromatic hydrocarbon desorption'. Chemosphere, Vol. 43, No. 8, pp. 1013-1021.

Yao, F., Yu, G., Bian, Y., et al. (2007), 'Bioavailability to grains of rice of aged and fresh ddd and dde in soils'. Chemosphere, Vol. 68, No. 1, pp. 78-84.

Zhu, Y., Zhang, S., Huang, H., et al. (2009), 'Effects of maize root exudates and organic acids on the desorption of phenanthrene from soils'. Journal of Environmental Sciences, Vol. 21, No. 7, pp. 920-926. 


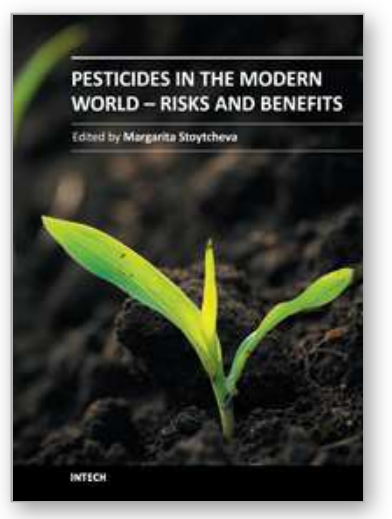

\author{
Pesticides in the Modern World - Risks and Benefits \\ Edited by Dr. Margarita Stoytcheva
}

ISBN 978-953-307-458-0

Hard cover, 560 pages

Publisher InTech

Published online 03, October, 2011

Published in print edition October, 2011

This book is a compilation of 29 chapters focused on: pesticides and food production, environmental effects of pesticides, and pesticides mobility, transport and fate. The first book section addresses the benefits of the pest control for crop protection and food supply increasing, and the associated risks of food contamination. The second book section is dedicated to the effects of pesticides on the non-target organisms and the environment such as: effects involving pollinators, effects on nutrient cycling in ecosystems, effects on soil erosion, structure and fertility, effects on water quality, and pesticides resistance development. The third book section furnishes numerous data contributing to the better understanding of the pesticides mobility, transport and fate. The addressed in this book issues should attract the public concern to support rational decisions to pesticides use.

\title{
How to reference
}

In order to correctly reference this scholarly work, feel free to copy and paste the following:

Zhao Zhenhua, Xia Liling, Wang Fang and Jiang Xin (2011). Effects of Low-Molecular-Weight-Organic-Acids on the Release Kinetic of Organochlorine Pesticides from Red Soil, Pesticides in the Modern World - Risks and Benefits, Dr. Margarita Stoytcheva (Ed.), ISBN: 978-953-307-458-0, InTech, Available from: http://www.intechopen.com/books/pesticides-in-the-modern-world-risks-and-benefits/effects-of-low-molecularweight-organic-acids-on-the-release-kinetic-of-organochlorine-pesticides-fr

\section{INTECH}

open science | open minds

\author{
InTech Europe \\ University Campus STeP Ri \\ Slavka Krautzeka 83/A \\ 51000 Rijeka, Croatia \\ Phone: +385 (51) 770447 \\ Fax: +385 (51) 686166 \\ www.intechopen.com
}

\author{
InTech China \\ Unit 405, Office Block, Hotel Equatorial Shanghai \\ No.65, Yan An Road (West), Shanghai, 200040, China \\ 中国上海市延安西路65号上海国际贵都大饭店办公楼 405 单元 \\ Phone: +86-21-62489820 \\ Fax: $+86-21-62489821$
}


(C) 2011 The Author(s). Licensee IntechOpen. This is an open access article distributed under the terms of the Creative Commons Attribution 3.0 License, which permits unrestricted use, distribution, and reproduction in any medium, provided the original work is properly cited. 